\title{
Effect of chemical degradation followed by toothbrushing on the surface roughness of restorative composites
}

\author{
Fernanda Regina VOLTARELLI', Claudia Batitucci dos SANTOS-DAROZ', Marcelo Corrêa ALVES², \\ Andrea Nóbrega CAVALCANTI ${ }^{3}$, Giselle Maria MARCHI ${ }^{4}$
}

1- DDS, MS, PhD, Piracicaba Dental School, State University of Campinas, Brazil.
2- Eng, PhD student, Piracicaba Dental School, State University of Campinas, Brazil.
3- DDS, MS, PhD, Associate Professor, Dental School, Federal University of Bahia, Brazil.
4- DDS, MS, PhD, Professor, Piracicaba Dental School, State University of Campinas, Brazil.

Corresponding address: Fernanda Regina Voltarelli - Rua Orlando Pavan, 127 - Jardim Rosolem - Hortolândia, SP - $13185-300$ - Brasil - Phone: +55 19 21065337 - Fax: +55 1921065200 - e-mail: fervoltarelli@hotmail.com

Received: March 18, 2009 - Modification: August 10, 2009 - Accepted: May 21, 2010

\section{ABSTRACT}

\begin{abstract}
bjectives: The aim of the present study was to assess the effect of the exposure to food-simulating liquids prior to brushing simulation on the surface roughness of five composite materials (Quixfil, Filtek Supreme, Esthet-X, Filtek Z250, Tetric Ceram). Material and Methods: Twenty cylinders ( $5 \mathrm{~mm}$ diameter and $4 \mathrm{~mm}$ height) of each composite were randomly allocated to 4 groups $(n=5)$, according to the food-simulating liquid in which they were immersed for 7 days at $37^{\circ} \mathrm{C}$ : artificial saliva, heptane, citric acid, and ethanol. After this period, the top surface of composite cylinders was submitted to 7,500 brushing cycles (200 g load). Measurements of the surface roughness $(\mathrm{Ra}, \mu \mathrm{m})$ were carried out before and after the exposure to the chemicals/brushing simulation. Changes on the morphology of composite surfaces were observed through scanning electron microscopy (SEM). Results: The statistical analysis (ANOVA with cofactor / Tukey's test, $\alpha=5 \%$ ) detected a significant interaction between solutions and composite resins. Esthet-X, Filtek Z250 and Tetric Ceram were not affected by the food-simulating liquids/toothbrushing. Citric acid and ethanol increased the surface roughness of Quixfil and Filtek Supreme, respectively. SEM images corroborate the surface roughness findings, demonstrating the negative effect from chemical solutions and mechanical abrasion. Conclusions: The surface roughness of composite resin materials are differently affected by the food-simulating solutions, depending on the immersion media.
\end{abstract}

Key words: Dental materials. Composite resins. Toothbrush. Solubility.

\section{INTRODUCTION}

In the past years, improvements on the mechanical properties of resin-based materials along with increased aesthetic demands have resulted on the enlarged use of direct composite resin restorations in anterior and posterior teeth ${ }^{22}$. Despite the notable advance in their composition and properties, composite materials must withstand a series of adverse conditions in the oral environment that challenges their integrity and longevity ${ }^{3}$. Progressive mechanical and environmental loads may result in matrix and/or filler deterioration, interfacial debonding, microcracking, and/or filler particle fracture ${ }^{4}$.

It has been suggested that superficial changes on restorative materials are partially associated to their chemical degradation, which can soften the external surface, making it more vulnerable to mechanical abrasion'. Some chemicals from food and drinks can lead to surface degradation of composite restorations, resulting in unaesthetic appearance and increased surface roughness, accelerating the wear of dental materials ${ }^{3,7}$. These effects might vary according to intrinsic characteristics of the material, such as its composition, or extrinsic characteristics, such as restorations finishing/polishing ${ }^{12}$.

Toothbrushing abrasion constitutes another 
important issue on wear processes ${ }^{8}$. Even though tooth brushing plays an important role in oral hygiene, its continuing action might damage the surface of resin composite restorations, making it rougher and, consequently, prone to staining, plaque accumulations, soft tissue inflammation and recurrent caries ${ }^{6,25}$. Although other works had been conducted to evaluate the effect of surface degradation on restorative composites, limited information is available concerning the association of toothbrush abrasion and chemical challenges. Thus, the aim of the present study was to evaluate the effect of the exposure to food-simulating liquids prior to toothbrushing simulation on the surface roughness of 5 composite materials with different compositions. The null hypothesis tested was that composite resins present similar surface roughness after immersion in the food-simulating solutions and brush simulation.

\section{MATERIAL AND METHODS}

\section{Specimen preparation}

Figure 1 lists the restorative materials used in the present study, along with their classification, manufacturers, batch numbers, and composition.

Twenty cylinders of each material were made using a cylindrical mold (5x4-mm dimension) which was filled with two 2-mm-thick increments from the respective composite. After the insertion of the last increment, a polyester strip and a 500-g weight were placed over the mold and left for $30 \mathrm{~s}$ to allow for a better accommodation of the composite. Each increment was light-cured for 20 s using a halogen light-curing unit (Optilux 501, Sybron Kerr, Danbury, CT, USA). The light output of the lightcuring unit was measured with its radiometer and was greater than $500 \mathrm{~mW} / \mathrm{cm}^{2}$.

Specimens received an identification number at the surface not directly exposed to the curing light, and were stored individually in recipients free from external light, containing $1 \mathrm{~mL}$ of distilled water, at $37^{\circ} \mathrm{C}$. After $24 \mathrm{~h}$, top surfaces were finished with silicon carbide abrasive papers of decreasing abrasiveness (600, 1200, and 2000-grit; Arotec Ind. Com. Ltd., Cotia, SP, Brazil) under water coolant. A final polish was performed with soft cloths and diamond pastes (6-, 3-, and 1- $\mu \mathrm{m}$; Arotec Ind. Com. Ltd., Cotia, SP, Brazil). Specimens were ultrasonically cleaned for 20 min after each finishing/polishing step.

\section{Chemical and mechanical degradation}

The 20 specimens from each composite were randomly distributed into four groups $(n=5)$ according to the respective solution in which they were immersed: As - Artificial saliva (Hank's solution); He - Heptane P.A.; Ca - Citric acid $0.02 \mathrm{M}$; Et - Ethanol 50\%. He, Ca and Et are mediums recommended by the FDA (1976) to be used as food-simulating liquids ${ }^{5}$. Their respective composition and the type of food they represent are depicted in Figure 2. Specimens were stored for 7 days in the respective solution in a light-free ambient at $37^{\circ} \mathrm{C}$. After this period, specimens were ultrasonically cleaned to remove residuals from the chemical solutions.

After the exposure to the chemical solutions, specimens were submitted to 7,500 brushing cycles under a vertical load of $200 \mathrm{~g}$, simulating a period of approximately six months of toothbrushing ${ }^{21}$. Toothbrushes with compact head and soft nylon bristles were adapted in the toothbrushing simulating machine (Equilabor brushing machine; Equilabor, Piracicaba, SP, Brazil). This apparatus provided linear toothbrushing movements across the specimens at a speed of 250 cycles per min, with a double pass of the brush head over the surface.

\begin{tabular}{|c|c|}
\hline Material/Manufacturer & Composition \\
\hline $\begin{array}{c}\text { Quixfil / Dentsply DeTrey Konstanz, } \\
\text { Germany }\end{array}$ & $\begin{array}{c}\text { UDMA, TEGDMA, Di- and trimethacrylate resins, carboxylic acid } \\
\text { modified dimethacrylate resin, BHT, UV stabilizer, Camphorquinone, } \\
\text { Ethyl-4-dimethylaminobenzoate, Silanated strontium aluminum sodium } \\
\text { fluoride phosphate silicate glass }\end{array}$ \\
\hline $\begin{array}{c}\text { Filtek Supreme / 3M ESPE, St. Paul, MN, } \\
\text { USA }\end{array}$ & Bis-GMA, UDMA, Bis-EMA, TEGDMA, nanosilica filler \\
\hline $\begin{array}{c}\text { Esthet-X / Dentsply DeTrey Konstanz, } \\
\text { Z250 / 3M ESPE, St. Paul, MN, USA }\end{array}$ & $\begin{array}{c}\text { Urethane modified Bis-GMA-adduct, Bis-EMA, TEGDMA, photo initiators, } \\
\text { stabilizers, boro barium-aluminium fluorosilicate glass, highly dispersed } \\
\text { silicon dioxide }\end{array}$ \\
\hline $\begin{array}{c}\text { Tetric Ceram HB / Ivoclar Vivadent, Schaan, } \\
\text { Liechtenstein }\end{array}$ & $\begin{array}{c}\text { Bis-GMA, UDMA, decandiol dimethacrylate, barium glass, barium- } \\
\text { aluminium fluorosilicate glass, ytterbium trifluoride, silicon dioxide, } \\
\text { speroid mixed oxide, additives, catalysts, stabilizers, pigments }\end{array}$ \\
\hline
\end{tabular}

Abbreviations - Bis-GMA: Bisphenol A diglycidyl ether dimethacrylate; TEGDMA: triethylene glycol dimethacrylate; BHT: Butylated hydroxy toluene; UEDMA: Uurethane dimethacrylate monomer; Bis-EMA: Ethoxylated bisphenol-A-dimethacrylate

Figure 1- Restorative materials used in the present study, manufacturers and composition 


\begin{tabular}{|l|c|}
\hline Immersion media & Type of simulation \\
\hline & \\
\hline Hank's solution & Artificial saliva \\
\hline Heptane P.A. & butter, fat meats and vegetable oils \\
\hline 0.02 M Citric acid & beverages, vegetables, fruits, candy and syrup \\
\hline $50 \%$ Ethanol & alcoholic beverages, mouth rinsing \\
\hline
\end{tabular}

Figure 2- Food-simulating liquids used

Toothbrushes were replaced after the completion of each brushing cycle. During brushing simulation, specimens were kept in distilled water.

\section{Surface roughness}

Surface roughness measurements were conducted on the top surface of composite specimens in two moments: after the polishing procedure (baseline) and after the end of mechanical toothbrushing. Measurements were carried out using a surface profilometer (Surfcorder SE 1700, Kosakalab, Tokyo, Japan), with a 2- $\mu$ m diameter tip. The Ra parameter $(\mu \mathrm{m})$ was adopted. In each surface, three sequential readings were performed, with a length of $1.25 \mathrm{~mm}$, a cutoff of $0.25 \mathrm{~mm}$ and a speed of $0.1 \mathrm{~mm} / \mathrm{s}$. The Ra of each specimen was obtained from the arithmetic mean of its three Ra readings.

\section{Statistical analysis}

The statistical analysis of Ra values was done by ANOVA using baseline roughness means as covariables. Multiple pairwise comparisons were done with Tukey post-hoc test. Analyses were carried out with a 0.05 significance level.

\section{Scanning electron microscopy (SEM)}

Changes in superficial topography provided by the methods of chemical/mechanical degradation were observed by SEM. In order to isolate the effect of the different experimental conditions, 10 specimens from each restorative material were performed and submitted to the following conditions: toothbrushing alone (TB); immersion in food-simulating solutions (As, $\mathrm{He}, \mathrm{Ca}$ or, Et); association of TB and food-simulating solutions
(As+TB, He+TB, Ca+TB, Et+Tb) and control (C/not submitted to any surface treatment). Specimens were mounted on metallic stubs, dried at $37^{\circ} \mathrm{C}$ for 48 h, gold-sputter coated (Desk II cold sputter/ etch unit, Dentron Vaccum Inc, Moorestown, NJ, USA), and evaluated under a scanning electron microscope (JSM 5600SLV; Jeol Datum, Akishima, Tokyo, Japan).

\section{RESULTS}

The overall results (ANOVA using baseline roughness means as co-variables) indicated significant interaction between chemical solutions (Table 1). After immersion and toothbrushing, the Ra of Quixfil (Dentsply, DeTrey Konstanz, Germany) and Filtek Supreme (3M ESPE, St. Paul, MN, USA) varied according to the food-simulating liquid. Surface roughness values and standard deviations are shown in Table 1. Quixfil presented significantly rougher surfaces after immersion in citric acid, compared to the other solutions. On the other hand, Filtek Supreme presented significantly higher surface roughness when exposed to ethanol compared to artificial saliva. Esthet-X (Dentsply, DeTrey), Filtek Z250 (3M ESPE, St. Paul, MN, USA) and Tetric Ceram (Ivoclar Vivadent, Schaan, Liechtenstein) presented similar surface roughness, regardless of the immersion in chemicals previous to the brushing simulation.

The changes on superficial topography provided by toothbrushing, food-simulation solutions and their association were qualitatively evaluated under the SEM. These images have illustrated the distinct and adverse effects of each chemical solution on restorations surfaces compared with their

Table 1- Surface roughness means $(\mathrm{Ra}, \mu \mathrm{m})$ and standard deviations after immersion in the food-simulating solutions and brush simulation

\begin{tabular}{lccccc}
\hline Immersion Media & Esthet-X & Quixfil & Filtek Supreme & Tetric Ceram HB & Filtek Z250 \\
\hline & & & & & \\
Hank & $0.22(0.05) \mathrm{A}$ & $0.18(0.02) \mathrm{B}$ & $0.08(0.04) \mathrm{B}$ & $0.13(0.03) \mathrm{A}$ & $0.10(0.01) \mathrm{A}$ \\
Citric Acid & $0.17(0.06) \mathrm{A}$ & $0.63(0.02) \mathrm{A}$ & $0.12(0.04) \mathrm{AB}$ & $0.19(0.04) \mathrm{A}$ & $0.11(0.01) \mathrm{A}$ \\
Heptane & $0.17(0.06) \mathrm{A}$ & $0.14(0.02) \mathrm{B}$ & $0.11(0.04) \mathrm{AB}$ & $0.11(0.03) \mathrm{A}$ & $0.11(0.01) \mathrm{A}$ \\
Ethanol & $0.10(0.05) \mathrm{A}$ & $0.13(0.02) \mathrm{B}$ & $0.23(0.04) \mathrm{A}$ & $0.10(0.03) \mathrm{A}$ & $0.12(0.01) \mathrm{A}$ \\
\hline
\end{tabular}

Different letters indicate statistically significant differences (Tukey test, $\alpha=5 \%$ ). Uppercase letters compare immersion media. 

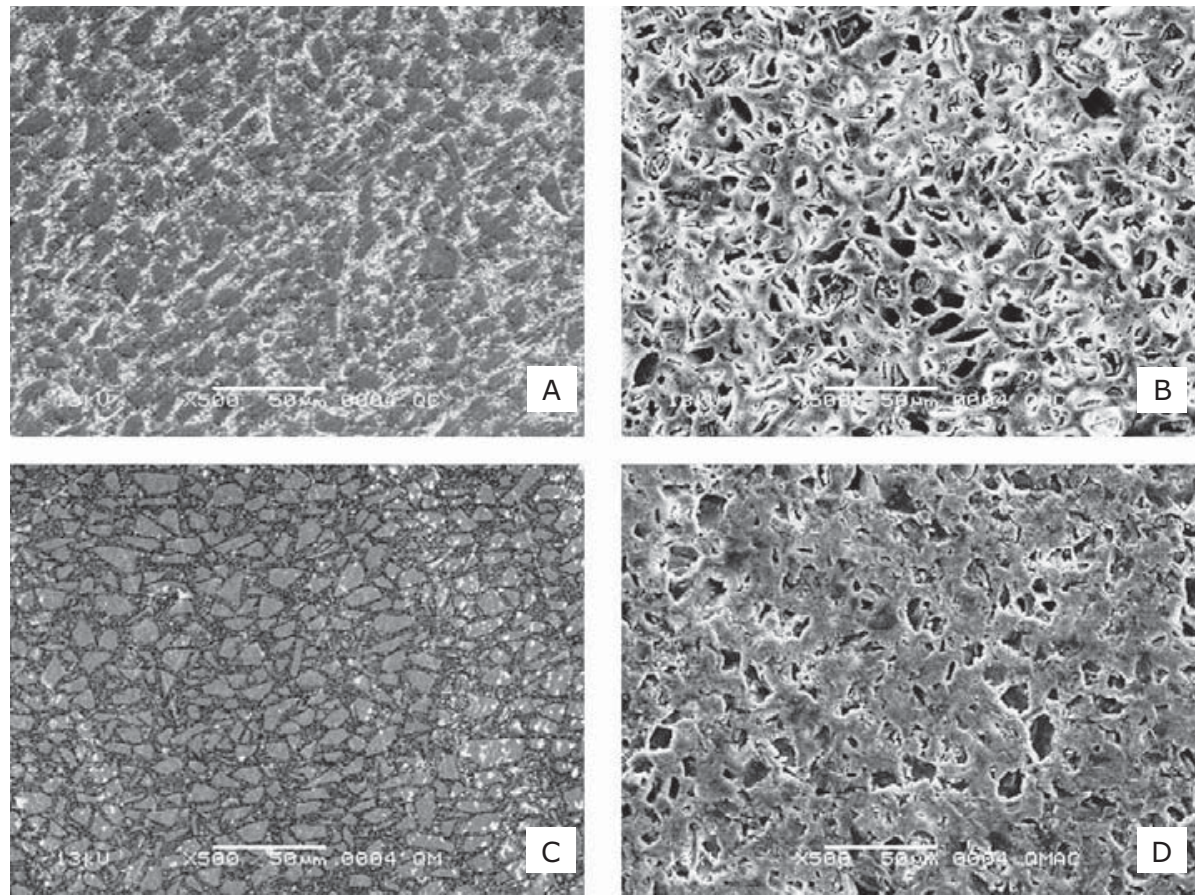

Figure 3- Changes on the morphology of Quixfil evaluated by scanning electron microscopy: Control (A); Immersion in citric acid (B); Toothbrush abrasion (C); Toothbrush abrasion after immersion in citric acid (D)
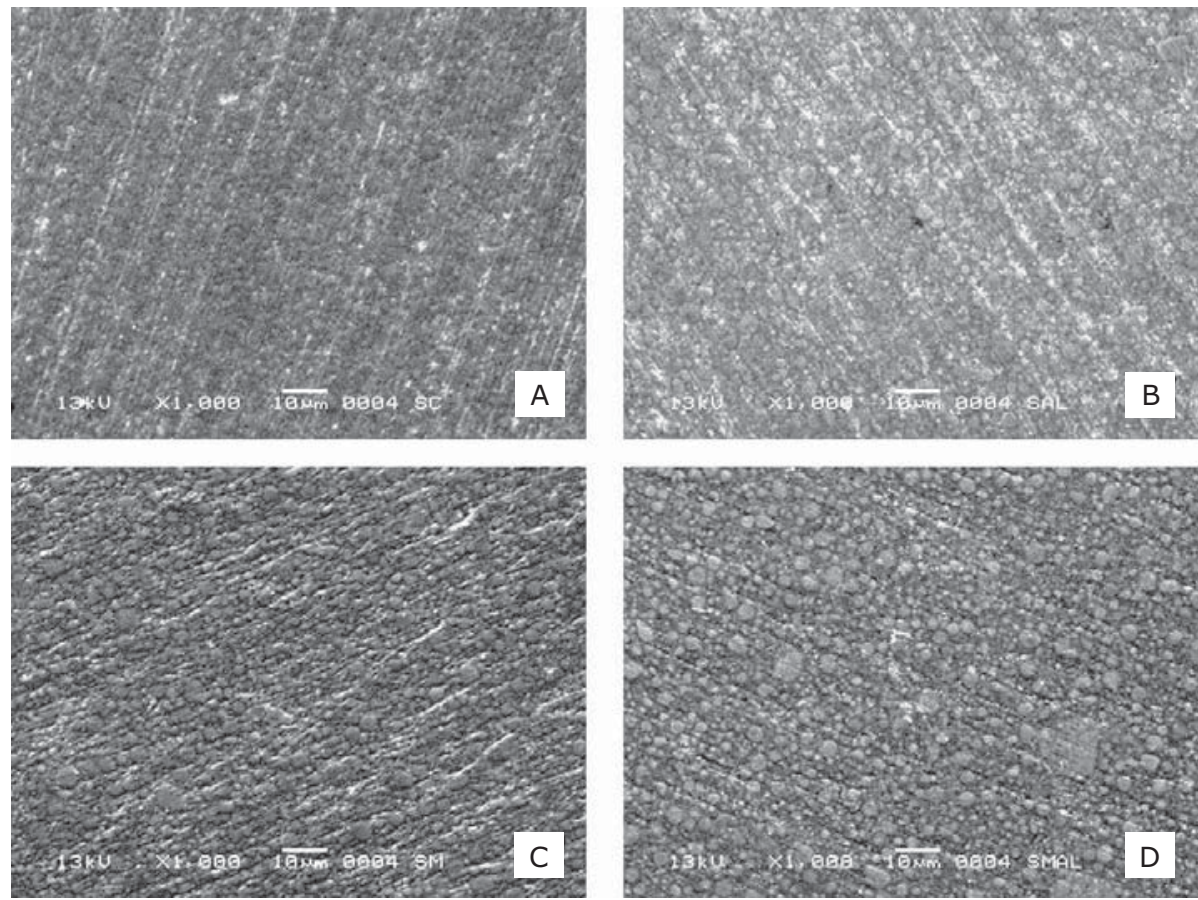

Figure 4- Changes on the morphology of Filtek Supreme evaluated by scanning electron microscopy: Control (A); Immersion in ethanol (B); Toothbrush abrasion (C); Toothbrush abrasion after immersion in ethanol (D)

respective control (Figure $3 A-B$ and $4 A-B$ ). Images also have indicated that toothbrushing simulation resulted in superficial loss of organic matrix (Figure $3 \mathrm{C}$ and $4 \mathrm{C}$ ). The effect of the association between toothbrushing and the immersion in food-simulating liquids depended on the initial result from the chemical degradation (Figure 3D and 4D).

\section{DISCUSSION}

The surface texture of dental materials plays a major role on plaque accumulation, wear and discoloration of composite restorations, which may eventually impair their aesthetic appearance, as long as other factors such as shade, shape and contour of the restoration?. Previous studies 
have demonstrated superficial changes on dental composites caused by some food-simulating liquids. Such alterations have been attributed to the degradation of the polymer matrix and of the resinfiller interface, and to the loss of inorganic filler particles $^{9,24}$. In the oral environment, composite materials may either be exposed intermittently or continuously to chemical agents found in saliva, food and beverages ${ }^{1,19,23}$. Intermittent exposure occurs during eating or drinking until teeth are cleaned. Continuous exposure may, however, occur as chemical agents can be absorbed by adherent debris (such as calculus or food particles) or be produced by bacterial decomposition of debris ${ }^{23}$. In the present study, the exposure of composite resin materials to the food-simulating liquids was conducted throughout continued immersion in the respective solution for 7 days at $37^{\circ} \mathrm{C}$. This period of immersion was chosen to accelerate the effect of the food-simulating liquids, being in accordance to previous methods described in the literature ${ }^{22,24}$.

In the same way as the chemical degradation, toothbrushing might provide some superficial changes on composite materials ${ }^{12,14}$. In a clinical situation, toothbrushing might come just after the exposure to chemical agents. Although some studies have investigated the separate effects of food-simulating liquids and toothbrushing on the surface roughness of dental composites, the influence of such association is also clinically relevant.

The null hypothesis tested in this study was rejected since the findings indicated that the surface roughness of composite materials varied according to the type of solution in which they were immersed before toothbrushing simulation. For the composite Quixfil, immersion in artificial saliva, heptane and ethanol resulted in similar surface roughness. On the other hand, the chemical degradation provided by the citric acid increased the surface roughness. This finding could be corroborated in the SEM images, which have shown a significant loss of filler particles after immersion (Figure 3B). In accordance with the findings of a previous study ${ }^{2}$, fillers containing alkaline metals, such as the ones presented in Quixfil composite (silanated strontium aluminum sodium fluoride phosphate silicate glass), are highly susceptible to corrosion, especially under the influence of hydrogen ions. For this reason, ions released from the citric acid solution might have induced the lixiviation and loss of composite fillers, consequently increasing the surface roughness. Although the present study did not aim to compare the $\mathrm{pH}$ differences among the food simulating solutions used, it is known that greater fillers loss can be expected when composite materials are exposed to low $\mathrm{pH}$ solutions such as the citric acid ( $\mathrm{pH} 3.0)$, since such media might increase the erosion of polymeric chains ${ }^{11,20}$.

Although low pH solutions can negatively affect the properties and morphology of composite resins; in the present study, this could only be observed for Quixfil. For the other types of composite resins tested, the $\mathrm{pH}$ of the solution media did not play a significant role over the composites final surface roughness after a period of 7 days of storage. However, a longer storage period may result in greater statistical significance. Therefore, further studies are needed to investigate and elucidate the effect of different $\mathrm{pH}$ solutions on composites surface topography and mechanical properties.

As it could be observed in the SEM images, the toothbrushing procedure performed after the immersion in citric acid resulted in the removal of part of the organic matrix around the loosen fillers (Figure 3D). This result might be associated to a lower hardness of the organic matrix compared to that of the filler particle ${ }^{15}$.

Another finding of the present study was that the immersion in ethanol prior to toothbrushing has increased the surface roughness of Filtek Supreme composite. SEM images also have validated this result, and have indicated areas of abraded organic matrix and loosen fillers (Figure $4 B$ ). Surface changes might have progressed in the following sequence ${ }^{8}$ : first, the immersion in the chemical solution have provided changes on the softer resinous matrix, causing the exposure or protrusion of the harder filler particles; then, during toothbrushing, the protruding filler particles are dislodged 8 .

This finding might be associated with the solubility of the resin matrix of Filtek Supreme in ethanol, which presents Bis-GMA molecules ${ }^{10,11,13,17}$. According to the results of a previous study, the chemical degradation provided by the ethanol is related to the smoothening of the polymeric chain, resulting in its partial loss on materials surface ${ }^{1}$. In accordance to Yap, et al. ${ }^{23}$ (2001), solutions with solubility parameters around $3 \times 10^{4} \mathrm{~J}^{1 / 2} \mathrm{~m}^{-3 / 2}$ will produce significant damages on Bis-GMA based composites ${ }^{13,17}$. As occurred with Quixfil specimens immersed in citric acid, the immersion in ethanol have rendered the Filtek Supreme material excessively smooth to resist the toothbrushing procedure ${ }^{3}$.

The absence of ethanol effect over the other materials that also present Bis-GMA in their composition (Z250 and Tetric Ceram HB) can be explained by the degree of conversion of Filtek Supreme. According to Silva, et al. ${ }^{18}$ (2008), resin composite with mean filler particle size in the nanoscale results in lower light transmittance compared to hybrid composites. The light that passes through the resin composite is scattered by the small filler particles. The non-agglomerated 
silica nanoparticles of Filtek Supreme with mean size of $20 \mathrm{~nm}$ might have caused the light-scattering effect. ${ }^{18}$ Thus, according to Sideridou, et al. ${ }^{16}(2006)$ the extractable amount of unreacted monomer depends on the degree of conversion; the lower the degree of conversion the higher the amount of unreacted monomer that can be released from the material ${ }^{13,16}$. On the other hand, the more the degradation of the organic matrix, more filler particles can be lost, what results in a material with increased surface roughness.

\section{CONCLUSIONS}

Within the limitations of this study, it may be concluded that surface roughness of composite resin materials are differently affected by the foodsimulating solutions, depending on the immersion media. In addition, the brushing procedure performed immediately after chemical degradation led to an increase in surface roughness under in vitro conditions.

\section{ACKNOWLEDGEMENTS}

The authors thank Dentsply, Ivoclar/Vivadent and $3 M / E S P E$ for the kind donation of materials for this research.

\section{REFERENCES}

1- Akova T, Ozkomur A, Uysal H. Effect of food-simulating liquids on the mechanical properties of provisional restorative materials. Dent Mater. 2006;22:1130-4.

2- Attin T, Buchalla W, Hellwig E. Effect of topical fluoride application on toothbrushing abrasion of resin composites. Dent Mater. 2006;22:308-13.

3- Badra VV, Faraoni JJ, Ramos RP, Palma-Dibb RG. Influence of different beverages on the microhardness and surface roughness of resin composites. Oper Dent. 2005;30:213-9.

4- Drummond JL. Degradation, fatigue, and failure of resin dental composite materials. J Dent Res. 2008;87:710-9.

5- Food and Drug Administration. FDA guidelines for chemistry and technology requirements of indirect additive petitions. Washington, DC: FDA; 1976.

6- Garcia FC, Wang L, D'Alpino PH, Souza JB, Araujo PA, Mondelli RF. Evaluation of the roughness and mass loss of the flowable composites after simulated toothbrushing abrasion. Braz Oral Res. 2004; 18:156-61.

7- Heintze SD, Forjanic M. Surface roughness of different dental materials before and after simulated toothbrushing in vitro. Oper Dent. 2005;30:617-26.
8- Kawai K, Iwami Y, Ebisu S. Effect of resin monomer composition on toothbrush wear resistance. J Oral Rehabil. 1998;25:264-8. 9- Larsen IB, Munksgaard EC. Effect of human saliva on surface degradation of composite resins. Scand J Dent Res. 1991;99:25461.

10- Lopes LG, Jardim AV Filho, Souza JB, Rabelo D, Franco EB, Freitas GC. Influence of pulse-delay curing on sorption and solubility of a composite resin. J Appl Oral Sci. 2009;17(1):27-31. 11- Medeiros IS, Gomes MN, Loguercio AD, Rodrigues LE Filho. Diametral tensile strength and Vickers hardness of a composite after storage in different solutions. J Oral Sci. 2007;49:61-6. 12- Neme AL, Frazier KB, Roeder LB, Debner TL. Effect of prophylactic polishing protocols on the surface roughness of esthetic restorative materials. Oper Dent. 2002;27:50-8.

13- Polydorou O, König A, Hellwig E, Kümmerer K. Long-term release of monomers from modern dental-composite materials. Eur J Oral Sci. 2009;117:68-75.

14- Santos PH, Pavan S, Consani S, Correr Sobrinho L, Sinhoret MA, Arioli JN Filho. In vitro evaluation of surface roughness of 4 resin composites after the toothbrushing process and methods to recover superficial smoothness. Quintessence Int. 2007;38:e24753.

15- Senawongse P, Pongprueksa P. Surface roughness of nanofill and nanohybrid resin composites after polishing and brushing. J Esthet Restor Dent. 2007;19:265-73.

16- Sideridou ID, Achilias DS, Karabela MM. Sorption kinetics of ethanol/water solution by dimethacrylate-based dental resins and resin composites. J Biomed Mater Res B Appl Biomater. 2007;81(1):207-18.

17- Sideridou ID, Karabela MM, Vouvoudi EC. Volumetric dimensional changes of dental light-cured dimethacrylate resins after sorption of water or ethanol. Dent Mater. 2008;24:1131-6. 18- Silva EM, Almeida GS, Poskus LT, Guimarães JGA. Relationship between the degree of conversion, solubility and salivary sorption of a hybrid and a nanofilled resin composite. J Appl Oral Sci. 2008;16(2):161-6.

19- Turssi CP, Magalhães CS, Serra MC, Rodrigues AL Jr. Surface roughness assessment of resin-based materials during brushing preceded by $\mathrm{pH}$-cycling simulations. Oper Dent. 2001;26:576-84. 20- Valinoti AC, Neves BG, Silva EM, Maia LC. Surface degradation of composite resins by acidic medicines and $\mathrm{pH}$-cycling. J Appl Oral Sci. 2008;16(4):257-65.

21- van Dijken JW, Ruyter IE. Surface characteristics of posterior composites after polishing and toothbrushing. Acta Odontol Scand. 1987;45:337-46.

22- Yap AU, Low JS, Ong LF. Effect of food-simulating liquids on surface characteristics of composite and polyacid-modified composite restoratives. Oper Dent. 2000;25:170-6.

23- Yap AU, Tan SH, Wee SS, Lee CW, Lim EL, Zeng KY. Chemical degradation of composite restoratives. J Oral Rehabil. 2001;28:1015-21.

24- Yap AU, Wattanapayungkul $P$, Chung SM. Influence of the polymerization process on composite resistance to chemical degradation by food-simulating liquids. Oper Dent. 2003;28:7237.

25- Yap AU, Wu SS, Chelvan S, Tan ES. Effect of hygiene maintenance procedures on surface roughness of composite restoratives. Oper Dent. 2005;30:99-104. 